\title{
Nerve block enhances the success rate in arterio-venous shunt operation in patients of chronic renal failure
}

\author{
Salah Masoud, Eman Darweesh, Khalid Abdelal \\ Department of anesthesia and Icu, Sohag University, Egypt.
}

\begin{abstract}
:
the aim of this study is to compare two anesthetic modalities commonly used for shunt creation surgery in the patients of end-stage renal disease, two common anesthetic modalities are compared in this study as regard suitability and enhancement of outcomes on short and long time ,the two methods were sonographic guided supraclavicular nerve block using bupivacaine local anesthetic, or local infiltration of bupivacaine at the surgical site, follow-up of 20 patients from each group revealed that nerve block not only was more comfortable for both patient and surgeon but also it enhanced the blood flow across the shunt detected by duplex scan performed 4 hours post-operative ( $p$-value 0.002), also improves success rate of shunt detected by 4 months follow up, this may be explained by venous vasodilatation produced by sympathectomy that enhances blood flow at early hours and helps canalization of the shunt at the early hours of the shunt creation.
\end{abstract}

Keywords: supraclavicular nerve block, shunt success, patient satisfaction

\section{Introduction:}

Nerve block techniques play a major rule in the management of upper limb procedures providing both anesthesia and postoperative analgesia, Brachial plexus block can greatly simplify anesthetic management especially in patients with comorbidities who are not fit for other anesthetic modalities (1-3). one of the most common co-morbidities that make an obstacle for an anesthesiologist is chronic renal failure, those patients suffer a group of medical problems that may make general anesthesia contraindicated eg: metabolic acidosis, electrolyte imbalance, severe anemia, uraemic, encephalopathy, and others. (3-5). An arteriovenous shunt is the optimal form of vascular access in patients with renal failure requiring hemodialysis. Unfortunately, approximately one-third of fistulae fail at an early stage after creation. $(2,4,6)$. brachial plexus block results in arterio-venous dilation and improves outcomes of short and long term (7-9). This clinical study is to large trial to show the effect of nerve block on long-term shunt function, The study aims to compare whether a regional anesthetic block, compared to local anesthetic infiltration, can improve long-term fistula patency or not (10-14).

\section{patient and methods :}

This study was a single observerblinded, randomized controlled trial. Patients scheduled to have arteriovenous shunt operation in Sohag university hospital are already on dialysis (patients with chronic renal failure), After approval of ethics of research committee at Sohag University, A written informed consent from all patients was taken ,patients are all allowed to withdraw at any time from the research with no negative consequences on medical service production ,All medical data were confidential and collected for scientific research purposes, 40 adult patients with chronic renal failure 
were selected aged 60 to 85 years who are competent to give written consent scheduled for arterio-venous shunt creation operation between the brachial artery and cephalic vein,Exclusion criteria were Patient refusal of maneuver, Allergy to local anesthetic, Coagulopathy, Infection at the anesthetic or surgical site.

The choice of the anesthetic modality was dependent on patient choice, some patients preferred receiving the ultrasound-guided nerve block to get benefit from longer duration of block and analgesia, others refused when they are informed about possible complications Patients are randomized into two groups:

Group (A): received the ultrasoundguided supraclavicular nerve block using ( 30) $\mathrm{ml}$ of Bupivacaine (0.375) concentration

Group (B): received local infiltration anesthesia at the surgical site using the same local anesthetic agent (30) $\mathrm{ml}$ of Bupivacaine (0.375) concentration

The two groups were observed under monitoring with pulse oximetry, noninvasive blood pressure monitoring, ECG monitoring, and pain monitoring scale as will be described

Nerve block technique: the block was done under complete aseptic conditions, head of the bed elevated 45 degree the patient was asked to turn his head on the opposite side and have his shoulders down. A linear transducer put in the supraclavicular fossa. the brachial plexus was identified using the ultrasound, local anesthesia was introduced by needle, an echogenic facet-tip, 21- gauge needle with fixed extension tubing has been used to inject the local anesthetic agent through the roots of the brachial plexus. deep, middle, and superficial nerve trunks of the brachial plexus were injected under sonar-guide. Good aspiration must be done first to avoid intravascular injection. Patients were instructed to report any sign of local anesthetic toxicity like tinnitus, circumoral numbness, or headedness that would suggest possible intravascular injection so that injection should be stopped. On completion of the maneuver, the patient is moved to the operative room to undergo the surgical operation.

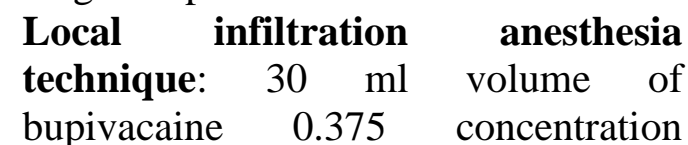
infiltrated at the surgical site by the anesthesiologist, On completion of the procedure, the patient was asked to rate his or her pain level during the pain prick stimulation at the surgical site using the pain level descriptions from the Mankoski Pain Scale(Table) (1).

. Complications monitored were local anesthetic systemic toxicity, pneumothorax, Horner syndrome, inadvertent phrenic nerve block, and intra-neural nerve injection.

evaluation of anesthetic success:

Technical success: The loss of sensory and motor function in the intended region. Sensory block: The patient verbalizes impaired sensation when the hand and arm are rubbed.Motor block: The inability to lift or abduct the arm with control, Sensory return: The patient verbalizes returning of touch sensation when the hand and arm are rubbed. Motor return The ability to touch the nose with the index finger

Intra-operative monitoring items:Monitoring was be mainly focused on : Intraoperative vital signs monitoring (pulse, BP,spo 2 and ECG tracing),signs and symptoms of local anesthetic toxicity or intravascular injection, patient discomfort and inefficient block, complications of the procedure e.g: pneumothorax, ptosis, phrenic nerve block, According to the patient 
condition the decision to give sedation or not was made, sedation was in the form of intravenous midazolam 3-5 $\mathrm{mg}$, and intravenous fentanyl 1-2 $\mathrm{mcg} / \mathrm{kg} 5$.

\section{Post-operative}

assessment

parameters: Patient post-operative follow up will include the following:Sensory return time: this is evaluated by the postoperative visit, the patient is asked about the definite time of perception of pain at the wound site and the need of postoperative analgesia, Motor return time: the patient is asked about the time at which he was able to move his arm and touch the tip of his nose by his fingertip, Blood flow across the shunt: this is done 4 hours post-operative using duplex scan, the results are expressed in the form of $\mathrm{cm} / \mathrm{s}$, The radiologist is blinded as regard type of anesthesia given to the patient.

Shunt evaluation 4 months postoperative: this is done by a phone call to the patient and contact with the nephrologist to ask him about shunt patency and function.

Statistical analysis: All data collected were from chart review, Quantitative assessments were performed using Microsoft Excel for Mac 2010 version 14.5.7 and included minimum, maximum, and average values and $\mathrm{SD}, \mathrm{A}$ power analysis estimated that a sample size of 20 patients in each group would have a significant level of difference at ( $p$ value) less than 0.05 , Continuous data were reported as mean \pm SD and were analyzed using independent sample ttest, Categorical data were reported as percentages and were analyzed using the chi-square test, a ( $\mathrm{p}$-value)less than (0.05) was considered statistically significant .

\section{Results:}

The age of candidate patients ranging between 55-80 years, Gender was 12 male patients\&8 female for the group ( A ), 15 male patients, and 5 females for the group

(B).

\begin{tabular}{|l|l|l|l|l|}
\hline & $\begin{array}{l}\text { A(nerve block) } \\
(\mathrm{N}=20)\end{array}$ & $\begin{array}{l}\mathrm{B}(\text { local infiltration) } \\
(\mathrm{N}=20)\end{array}$ & P VALUE & significance \\
\hline Age (16) & $69+5.6$ & $70+5.6$ & 0.98 & NS \\
\hline $\begin{array}{l}\text { Gender } \\
\text { Male/female }\end{array}$ & $12 / 8$ & $15 / 5$ & 3.11 & NS \\
\hline Height(CM) & $162.5 \pm 3.5$ & $164 \pm 4$ & 0.2 & NS \\
\hline Weight(kg) & $73 \pm 2.1$ & $72 \pm 2$ & 0.13 & NS \\
\hline BMI & $26.75 \pm 1.06$ & $26.45 \pm 2.1$ & 0.57 & NS \\
\hline
\end{tabular}

Table (1) demographic data for age \&gender and body mass index

Data are expressed in the form of numbers and percentage, value is considered significant if $<$ $0.05 \quad \mathrm{NS}=$ non-significant $\mathrm{S}=$ significant $\quad \mathrm{HS}=$ highly significant

\begin{tabular}{|l|l|l|l|l|}
\hline & $\begin{array}{l}\text { A(nerve } \\
\text { block) }\end{array}$ & $\begin{array}{l}\text { B } \\
\text { (local } \\
\text { infiltration) }\end{array}$ & $\begin{array}{l}\text { P } \\
\text { VALUE }\end{array}$ & significance \\
\hline Procedure time in minutes & $8.5 \pm 4.94$ & $4 \pm 0$ & 0.0002 & HS \\
\hline $\begin{array}{l}\text { the Onset of sensory block in } \\
\text { minutes }\end{array}$ & $9.5 \pm 7.77$ & $6.5 \pm 2.1$ & 0.27 & NS \\
\hline $\begin{array}{l}\text { Duration of sensory block in } \\
\text { minutes }\end{array}$ & $775 \pm 64$ & $360 \pm 57$ & 0.0001 & HS \\
\hline The onset of motor block in minutes & $16 \pm 5.6$ & & & \\
\hline Duration of motor block in minutes & $776 \pm 37$ & & & \\
\hline
\end{tabular}

Table (2): time needed for the anesthesia procedure \&sensory and motor data 
SOHAG MEDICAL JOURNAL Nerve block enhances the success rate in arterio-venous shunt operation in patients Vol. 23 No. 3 July 2019

Data are expressed in the form of mean \pm SD .P value is considered significant if $<0.05$ $\mathrm{NS}=$ non-significant $\mathrm{S}=$ significant $\quad \mathrm{HS}=$ highly significant

There was a highly significant for the group (A) as there is no motor difference between the two groups in block in the group (B) onset and duration of sensory block, The data of motor block were specified

\begin{tabular}{|l|l|l|l|}
\hline & A(nerve block) & B(local infiltration) & P VALUE \\
\hline Range of pain score & $(0-1)$ & $(0-3)$ & 0.0008 \\
\hline Number of Satisfied patients & $18(90 \%)$ & $11(55 \%)$ & 0.131 \\
\hline Number of Satisfied surgeons & $18(90 \%)$ & $9(45 \%)$ & 0.0023 \\
\hline Sedation needing patients & $1(12)$ & $9(45 \%)$ & 0.00348 \\
\hline
\end{tabular}

Table (3): The results of pain monitoring according to Mankoski pain scale (15), sedation requirements, patient, and surgeon satisfaction were as the following:

The result was (p-value 0.0008 ) has great statistical significance meaning that pain scale was less for the group
(A), Patients satisfaction and surgeon satisfaction were both better in the group (A), Sedation requirements were less in the group $(\mathrm{A})$

\begin{tabular}{|l|l|l|l|}
\hline & A(nerve block) & B(local infiltration) & P-value \\
\hline $\begin{array}{l}\text { Duplex result in } \\
\mathrm{cm} / \text { minute }\end{array}$ & $140 \pm 23$ & $120 \pm 14$ & 0.002 \\
\hline $\begin{array}{l}\text { Number of } \\
\text { functioning shunt }\end{array}$ & $14(70 \%)$ & $12(60 \%)$ & 0.05 \\
\hline
\end{tabular}

Table (4): post-operative follow-up results. Data are expressed in the form of mean $\pm S D$

Blood flow across the shunt monitored by duplex scan 4 hours postoperative showing a better flow in the group (A), Shunt function was then monitored 4 months post-operative, the result was as shown in the table, the pvalue was 0.05 which is significant, There were no complications observed for neither procedure in neither group.

\section{Discussion}

This study is a blinded control study that was performed over 40 patients at Sohag university hospital , all patients have chronic renal failure, on dialysis and candidates for $\mathrm{A}-\mathrm{V}$ shunt creation, In a study published by Levent Sahin, MD,et al (14) that considered the same idea a comparison between nerve block and local infiltration anesthesia in shunt creation in this study infraclavicular nerve block was used instead of supraclavicular block ,and the local anesthetic agent used was a mixture of $0.5 \%$ of levobupivacaine $(10 \mathrm{ml})$ and $2 \%$ lidocaine $(10 \mathrm{ml})$,the study was performed over 60 patients (30 for each group) and then they followed their patients by duplex scan 3 hours ,7 days and 8 weeks postoperative and the results were as following :(data are expressed in form of mean $\pm \mathrm{SD}$ )

At 3 hours $69.6 \pm 7.9$ for nerve block group versus $44.8 \pm 13.8$ for local infiltration group with p-value .0001 , at 7 days $210.6 \pm 30.9$ for nerve block group versus $129 \pm 36.1$ for local infiltration group with p-value (.0001), at 8 weeks $680.6 \pm 70$ for nerve block group versus $405.3 \pm 76.2$ for local infiltration group with p-value .0001, Those results were obviously in favor of nerve block group as proved in our 
study, it is clear that blood flow is increasing with time in both groups as the process of arterialization of the vein is progressing

In our study, blood flow was measured (6) hours post-operative using duplex scan and the results were $140 \pm 23 \mathrm{~cm} / \mathrm{s}$ for the nerve block group (group A) versus $120 \pm 14 \mathrm{~cm} / \mathrm{s}$ for the (group B) that were anesthetized with local anesthesia with p-value (.002), The difference between the two studies was in timing of duplex performance while the same fact was proved that blood flow was better in nerve block group

\section{Conclusion}

Nerve block provides better sensory and motor block for the operation, more patient and surgeon satisfaction better blood flow across the shunt in the early postoperative period, less need for intraoperative sedation but with evidence of better long term effect on shunt function.

\section{References}

1. Ma IWY, Chun R, Kirkpatrick AW. Basics of Ultrasound. In: Ferrada P, editor. Ultrasonography in the ICU: Practical Applications. Cham: Springer International Publishing; 2015. p. 1-36.

2. Alan James Robert Macfarlane eTfopva, Nephrol Dial Transplant 2000. <1745-6215-14-263.pdf >.

3. Weir PHC, chronic eAfpw, renal disease AiCJoAA. Anesthesia for patients with chronic renal disease. Canadian Anaesthetists' Society Journal. 1984;31(4):468-80.

4. DEVANAND ANANTHAM MAE, MD,(ULTRASONOGRAPHY). Ultrasonography. 2016:348-59.e2.

5. Harold Ellis, Stanley Feldman, William Harrop-Griffiths Copyright (C) 1963, 1969, 1977.

6. van Es HW, Witkamp TD, Feldberg MAM. MRI of the brachial plexus and its region: anatomy and pathology. European Radiology. 1995;5(2):145-51.

7. Walji AH, Tsui BCH. Clinical Anatomy of the Brachial Plexus. In: Tsui BCH, Suresh S, editors. Pediatric Atlas of Ultrasound- and Nerve Stimulation-Guided Regional Anesthesia. New York, NY: Springer New York; 2016. p. 149-63.

8. Bevan DR. Anesthesia and Surgery in the Patient with Renal Failure. In: Suki WN, Massry SG, editors. Therapy of Renal Diseases and Related Disorders. Boston, MA: Springer US; 1991. p. 669-74.

9. Jankovic D. Brachial Plexus (Introduction and Anatomy). Regional Nerve Blocks in Anesthesia and Pain Therapy: Traditional and Ultrasound-Guided Techniques. Cham: Springer International Publishing; 2015. p. 341-7.

10. Kakiuchi $\mathrm{Y}$ eCdoflaiamipfpueaIJCPTN. <js-3-11.pdf $>$.

11. Hoeft MA e, Reg Anesth Pain Med 2005; 30(4): 414-460. Bupivacaine 2016.

12. Grouls RJ, Ackerman EW, Korsten $\mathrm{HH}, \quad$ Hellebrekers LJ, chromatography. J Chromatogr B Biomed Sci Appl1997; 694(2): 4215.1. 2016:397-465.14. Hull J, Heath e, Supraclavicular Brachial Plexus Block, Hemodialysis fA, Procedures A. Supraclavicular Brachial Plexus Block for Arteriovenous Hemodialysis Access Procedures. Journal of Vascular and Interventional Radiology. 2016;27(5):749-52.

13. Selander D DK, Lundborg G: Peripheral nerve injury, experdtinufraA, the mental study of the acute effects of needlepoint trauma A, Anaesthesiol Scand 21:182-188. $<$ nerve block complications.pdf $>$. 
14. Levent Sahin M, et al (Ultrasoundguided infraclavicular brachial plexus, Ultrasound-guided infraclavicular brachial plexus block enhances postoperative blood flow in arteriovenous fistulas. Journal of Vascular Surgery. 2011;54(3):74953.
15. Hull J, Heath e, Supraclavicular Brachial Plexus Block, Hemodialysis fA, Procedures A. Supraclavicular Brachial Plexus Block for Arteriovenous Hemodialysis Access Procedures. Journal of Vascular and Interventional 2016;27(5):749-52. 